\title{
EL SENTIDO DE UNA EDUCACIÓN EN MEDIOS
}

\author{
Roxana Morduchowicz $(*)$
}

SÍNTESIS: La educación en medios es un campo en torno al cual existen no pocas coincidencias en todo el mundo, basadas en la necesidad de acercar los medios de comunicación a la escuela como objeto de estudio y de análisis en la clase.

Sin embargo, esta expresión también suele definir distintas concepciones y enfoques. No todos los países coinciden en la manera de implementar y de encarar esta enseñanza, circunstancia que incluso se puede producir dentro de un mismo país. Algunas corrientes priorizan el enfoque semiológico y proponen el estudio del lenguaje de los medios. Otras son más sociológicas y analizan la relación de los niños y de los jóvenes con los medios. También están las que proponen examinar los efectos de los medios en la sociedad, sobre todo en la niñez (que últimamente han perdido peso). Finalmente, hay una corriente que plantea un enfoque crítico, más vinculado a los estudios culturales. Este artículo analiza, en definitiva, las diferentes concepciones que existen en torno a la educación en medios.

SÍNTESE: A educação em meios é um campo em torno do qual existem não poucas coincidências em todo o mundo, baseadas na necessidade de aproximar os meios de comunicação à escola como objeto de estudo e de análise na sala de aula.

No entanto, esta expressão também costuma definir diferentes concepções e enfoques. Nem todos os países coincidem na maneira de implementar e de encarar este ensino, circunstância que, inclusive, pode ser produzida dentro de um mesmo país. Algumas correntes priorizam o enfoque semiológico e propõem o estudo da linguagem dos meios. Outras são mais sociológicas e analisam a relação das crianças e dos jovens com os meios. Também estão as que propõem examinar os efeitos dos meios na sociedade, sobretudo, na infância (que ultimamente têm perdido peso). Finalmente, há uma corrente que apresenta um enfoque crítico, mais vinculado aos estudos culturais. Este artigo analisa, portanto, as diferentes concepções que existem em torno da educação em meios.

(*) Directora Nacional del Programa «Escuela y medios» del Ministerio de Educación, Ciencia y Tecnología de Argentina. 


\section{EL CONSENSO: LA NO TRANSPARENCIA}

Una educación en medios reconoce el papel central que desempeñan los medios de comunicación en la vida de los niños y de los jóvenes. Primera actividad de placer y principal fuente de información, los medios son el corazón de la vida política y cultural de las sociedades modernas, $y$, en este sentido, modifican y afectan la manera en que las personas perciben y comprenden la realidad.

Vivimos en una sociedad en la que el conocimiento está mediatizado. Casi todo lo que conocemos del mundo nos llega a través de los medios, que construyen una imagen de él, en virtud de la cual nosotros construimos la nuestra. Los medios de comunicación, y más recientemente las nuevas tecnologías, modifican nuestra percepción de la realidad, nuestra actitud ante el conocimiento y nuestra manera de concebir el mundo. Precisamente porque los medios son, ellos mismos, una representación del mundo.

La educación en medios analiza la manera en la que los medios construyen el mundo y actúan de mediadores entre él y nosotros. Se fundamenta sobre una noción esencial: los mensajes de los medios son construcciones. La educación en medios propone aprender a interrogar estas representaciones, a fin de comprender la forma en la que damos sentido a la realidad y el modo en que otros (los medios) le dan sentido para nosotros (Ferguson, 1994).

En suma, la educación en medios se funda sobre la idea central de que los medios no son transparentes. Este principio de no transparencia (Masterman, 1993) es el punto de partida de dicha formación, dirigida a confirmar y a fortalecer la idea de que los medios no son el simple reflejo de la realidad, sino que están implicados en su proceso de construcción. Los medios no son espejos que proyectan la imagen fiel de lo que sucede en el mundo. Por el contrario, sus mensajes presentan siempre puntos de vista particulares y diferentes sobre la manera en la que las audiencias deben interpretar la realidad.

Si bien en la actualidad existe cierto consenso en la definición de lo que es una educación en medios, la historia del vínculo entre la escuela y los medios de comunicación no siempre ha logrado ser tan clara y precisa.

Esa relación frecuentemente se ha movido más cerca de la desconfianza y de la condena que de la aceptación y el reconocimiento. La 
televisión, sobre todo, ha sido calificada por la escuela como un «enemigo poderoso», cuya influencia, por lo general negativa y manipuladora, debería combatirse. Tal actitud proteccionista y defensiva se enfrentó a quienes, en el extremo opuesto, se mostraban entusiasmados por el potencial ilimitado de los medios, considerados como una oportunidad para la democratización del saber y de la cultura, y como una expresión de la diversidad cultural y de la multiplicidad de manifestaciones sociales (Ferrés, 1994). Ambas actitudes conviven aún hoy dentro de un mismo sistema educativo, e incluso, con frecuencia, dentro de una misma escuela.

La educación en medios, sin embargo, no puede entenderse como protección, condena o idealización. Una educación en medios no basa sus principios en salvar o en proteger a los estudiantes. No se trata de censurar el placer ni de condenar a los alumnos por sus elecciones. Los juicios lineales suelen expresar preconceptos que a menudo sólo consiguen alejar aún más al docente de los consumos culturales de sus alumnos. Las valoraciones anticipadas buscan cerrar las discusiones antes que abrirlas. El objeto de una educación en medios no tiene como punto de partida la condena o la idealización de los medios ni de los usos que las audiencias hagan de ellos.

El eje de esta enseñanza - digámoslo una vez más- no es condenar ni celebrar los gustos mediáticos de los niños o de los jóvenes. Por el contrario, la educación en medios busca entender esa relación, analizar la manera en que los medios representan la realidad, y el modo en que las audiencias incorporan y resignifican los mensajes.

\section{LAS DIVERGENCIAS: LOS ENFOQUES}

Más allá de los consensos, la definición de una educación en medios suele ser motivo de debate internacional. Su significado y su objeto de estudio pueden ser muy diferentes según el país y los contextos social, político y cultural en los que se enmarque dicho abordaje.

Hay quienes piensan una educación en medios centrada en el estudio de los efectos manipuladores sobre los chicos, en especial de la televisión. Son quienes sostienen que esa formación debe ocuparse de analizar la manera en que la violencia, el sexo y el racismo representados en los programas televisivos, en los periódicos, en las revistas, y, más recientemente en los videojuegos, se reflejan en el comportamiento de los chicos. Analizan, entonces, la manera en que los medios influyen en la conducta de los niños y de los jóvenes. Esta corriente estudia los 
efectos de los medios de comunicación en las audiencias casi siempre de manera lineal y causal. La consecuencia es un enfoque más que todo normativo y de protección: las recomendaciones suelen centrarse en la necesidad de defender a los niños de los efectos amenazadores de los medios de comunicación.

Una segunda posición sostiene que la educación en medios debe entenderse como el análisis de las motivaciones personales de los chicos para la elección de sus gustos mediáticos. Así, los estudios que proponen se centrarán en explorar los consumos culturales de los jóvenes: programas de televisión que eligen, notas del periódico que leen, emisiones de radio que escuchan, revistas que compran, etc. Sus investigaciones se preguntan qué ven, qué leen y qué escuchan los chicos; por qué seleccionan determinados consumos culturales y no otros; de qué manera se apropian de los mensajes de los medios y qué relación construyen los más jóvenes con la cultura. Se trata, por lo general, de estudios más cercanos a la sociología de la comunicación, y que proponen un enfoque reflexivo sobre la relación que construyen los niños y los jóvenes con los medios de comunicación.

Una tercera tendencia propone una educación en medios cuyo eje es analizar el lenguaje de los medios, sus códigos y convenciones. Busca explorar la manera de nombrar y de decir el mundo. Se pregunta, por ejemplo, qué palabras utiliza el periódico para hablar de un tema específico; por qué eligió un cuerpo de letra (tipografía) para el titular; a qué imágenes recurrió el noticiero televisivo para una información; dónde se ha ubicado la cámara para lograr un determinado plano; qué música utiliza la telenovela en su presentación; con qué intención, etc. Se trata de un enfoque semiológico que analiza el lenguaje de los textos mediáticos en función de las representaciones que transmite.

Una cuarta y última corriente piensa la educación en medios a partir de las representaciones sociales que ofrecen para analizar su funcionamiento en el mundo real. Su propósito, en este caso, es entender los medios y las relaciones sociales en un contexto histórico y político específico. De qué manera los medios de comunicación mantienen, consolidan o subvierten las relaciones sociales existentes, es uno de los interrogantes principales de dicha corriente. Trascender el texto hacia el contexto es el eje que propone este enfoque crítico.

Los cuatro abordajes responden a posiciones muy diferentes y entienden de manera distinta la educación en medios. Hasta la década 
de los sesenta, la mayoría de los estudios y de las investigaciones giraba en torno a los efectos de los medios con base en metodologías cuantitativas: ¿cuánto tiempo de violencia ven los chicos en televisión por día y qué efectos provoca en sus conductas?

A partir de los ochenta se intensificaron las investigaciones cualitativas a través de las que se buscaba comprender la recepción de los mensajes. Los estudios de audiencia propusieron entonces analizar la manera en que los jóvenes se apropian de los medios, sin el estigma de los efectos negativos y lineales (de los medios a los niños), relegando la tradicional creencia del receptor pasivo y marginando concepciones conservadoras de la infancia. Los estudios sobre educación en medios comienzan a enfocarse interdisciplinariamente, e incluyen abordajes políticos, sociales y culturales con métodos más sofisticados y complejos.

De cualquier manera, y dado que las divisiones en el tiempo nunca son tan exactas, es necesario aclarar que las cuatro corrientes conviven aún hoy en diferentes países, definiendo de manera distinta los alcances y los objetivos de una educación en medios en cada contexto.

El primer enfoque (el de los efectos) ha sido superado desde los ochenta en la mayor parte del mundo, a excepción de los Estados Unidos, donde este abordaje tiene todavía hoy una singular importancia. El segundo enfoque (el reflexivo) responde a una dimensión sociológica, y, practicado en casi todos los países, es considerado como un insumo importante para la definición de las estrategias de una educación en medios. Entender la relación que los niños y los jóvenes construyen con los medios es fundamental para el diseño de esa enseñanza.

Los dos últimos enfoques son los más extendidos para definir la naturaleza de una educación en medios. Por un lado, la enseñanza de los medios como análisis del lenguaje para entender las representaciones que conducen sus mensajes. Por el otro, el abordaje crítico que busca ir más allá del texto para analizar las relaciones sociales en el universo real. Por ser precisamente los abordajes más extendidos, los analizaremos con más detalle.

\section{ENTRE EL TEXTO Y EL CONTEXTO}

El análisis del lenguaje es quizá el enfoque más popular en la educación en medios. Explorar la manera en que se organiza el espacio 
en un programa televisivo, qué dicen los presentadores de un noticiero, cuál es la vestimenta de un determinado personaje en una telenovela, qué música acompaña a una escena concreta, con qué tipografía titula una noticia un periódico, cómo es su adjetivación, cuál es el diseño de la página, etc., son interrogantes que explora la educación en medios en este enfoque semiológico a fin de entender las representaciones que el lenguaje circula.

Este abordaje, si bien importante, es insuficiente y encierra no pocos riesgos. Al circunscribirse al lenguaje, se olvidan otras dimensiones también necesarias para una educación en medios. El abordaje semiológico del discurso suele quedarse en el texto, y olvida o evita el análisis del contexto de producción y de recepción de los mensajes. Los medios y sus significados son productos de un tiempo político y económico determinado, cuyo análisis no es posible desconocer.

Los docentes que adoptan dicha posición (y que por lo general provienen del área de Lengua) suelen aplicar los mismos conceptos y categorías de análisis del discurso que utilizan en literatura para el análisis de las obras literarias (el estilo, la gramática, la construcción del personaje, la narración...). Acostumbran adoptar un paradigma de diferenciación en la selección de los textos (medios buenos y medios malos, textos buenos y textos malos), y, en ciertos casos, evitan todo abordaje político, económico, cultural y social, que, sin embargo, no puede dejar de incluir el análisis de la cultura popular.

El siguiente riesgo de una educación en medios basada sólo en el análisis del lenguaje es la inevitable enseñanza de los medios por separado. El lenguaje del periódico no es el mismo que el del cine, la radio o la televisión. Así, en no pocos países existen instituciones que se ocupan sobre todo del periódico, separadas de aquellas que abordan el cine o la televisión. En esos casos no existe un programa integrador (de todos los medios), ya que el fin de la educación en medios -en esta percepción- es el lenguaje. Sólo podría pensarse una educación en medios (en plural) si el lenguaje fuese una herramienta (importante ciertamente), y el objetivo entender mejor el mundo (mediado y representado en los medios) en el que vivimos.

La fragmentación de medios no es un tema menor. En primer lugar, impide valorar la importancia de la interacción que existe entre los diferentes medios. Vivimos en una época de convergencia tecnológi$\mathrm{ca}$, en la que las fronteras entre un medio y otro son muy sutiles. Es 
difícil entender un noticiero de televisión sin hacer referencia a la prensa escrita. La fragmentación de los medios impide un análisis de relación que exprese los vínculos dialécticos entre imágenes en movimiento, imágenes fijas, sonidos, música y palabras. Del mismo modo, analizar la publicidad en campañas multimedia es imposible si no se toma esa dimensión relacional.

Al tomar los medios por separado se dificulta también el análisis de las representaciones sociales, ya que tales representaciones suelen reforzarse entre los medios y dan lugar a valores y a estereotipos sólo comprensibles en el marco de un análisis integrado de todos los medios.

Finalmente, parece difícil estudiar los medios como industrias y agencias (propiedad de los medios, nacimiento de los grupos y de las corporaciones, etc.), una variable fundamental para la comprensión de los mensajes si se toma a los medios por separado. En la actualidad, las corporaciones nos recuerdan que las fronteras entre los medios de comunicación son cada vez más endebles. En el otro extremo de la cadena, la fragmentación en una educación centrada sólo en la prensa, en la televisión o en el cine impide un análisis profundo de las audiencias, ya que casi nadie es usuario exclusivo de un único medio de comunicación. Las personas utilizan los medios como sistemas interrelacionados.

Una vez más, dividir el análisis por medio de la comunicación sólo tiene sentido si el objetivo es el lenguaje, no si el mensaje es un paso para ir más allá. Una semiología que se precie de semiología social debe trascender el texto hacia el contexto y hacia las relaciones sociales del mundo real.

\section{REPRESENTACIÓN, PODER E IDENTIDAD}

¿Qué es entonces una educación en medios? Volvamos a nuestra definición original. La educación en medios consiste en analizar la manera en que los medios de comunicación (en plural y de manera integrada) construyen el mundo y se presentan como mediadores entre el universo y nosotros. Los medios de comunicación no sólo nos ayudan a saber más sobre el mundo, sino también a darle un determinado significado. Buscan estructurar nuestra comprensión del universo, incluyendo y excluyendo realidades, y ofreciendo mapas y códigos que marcan nuestro territorio. Los mensajes de los medios Ilevan consigo mecanis- 
mos significadores que estimulan ciertas manifestaciones y suprimen otras. En la representación reiterada de temas y de grupos sociales, los medios de comunicación buscan naturalizar el mensaje y simbolizar un determinado grupo social o un tema como normal y aceptable para el sentido común.

Los medios ejercen tres formas de poder: la primera es el poder de establecer la agenda (agenda setting), es decir, la capacidad que tienen para decidir, por inclusión o por exclusión, de qué se habla en los medios, y, en general, en la sociedad. La segunda es el poder de definir. Ya no se trata de decidir qué será representado sino cómo, es decir, la manera en que se habla de un tema o de un grupo social determinados. La tercera forma en que se puede manifestar el poder en los medios es mediante la representación de la normalidad. La repetición constante de una manera de hablar acerca de un grupo social en los medios puede llevar a considerarla como natural y normal para todos.

Los medios de comunicación fijan agendas, producen significados, forman opinión y construyen identidades. El impacto social de los medios es indiscutible. Sin embargo, las audiencias no son pasivas. No es posible hablar de una interpretación automática o de una decodificación de mensajes idéntica a la propuesta por el emisor. La relación entre el poder de los medios y la capacidad del receptor para resignificar el mensaje es siempre dialéctica. En la recepción y en el consumo, contrariamente a las connotaciones pasivas, ocurren movimientos de asimilación, de rechazo y de negociación de lo que los emisores proponen. Cada objeto destinado a ser consumido es un texto abierto que exige la cooperación del lector, del espectador, del usuario, para ser completado y significado. Todo bien es un estímulo para pensar, y, al mismo tiempo, un lugar imprevisto en el cual los receptores generan sentidos inesperados. Los mensajes se producen con instrucciones más o menos veladas, con dispositivos que inducen a lecturas. El receptor no es un creador puro, pero tampoco el emisor es omnipotente (García Canclini, 1999).

Por eso, analizar en esta perspectiva la cultura popular no es explorar la suma mecánica de los ofrecimientos de una industria cultural, sino estudiar la manera en que las audiencias los asumen y transforman. Al cine la gente va a verse en imágenes que le proponen al público modos de hablar, de moverse, de reconocerse. Se trata de analizar la producción y la recepción de una historia cultural que contextualiza ambas prácticas, a fin de comprender las formas de agrupación social y 
las de identidad que los medios contribuyen a legitimar. (Martín-Barbero, 1999).

La educación en medios, en este enfoque, promueve la reflexión de los alumnos en dos direcciones. Por un lado, analiza el papel de los medios como agenda pública para interrogar la manera en la que se definen las representaciones sociales, y para analizar el modo en que deciden lo que es normal y lo que queda excluido de esa normalidad. La educación en medios propone entonces estudiar el poder de esos medios: sus temas recurrentes, la presentación de los mensajes, los mecanismos significadores, el discurso, los códigos de naturalización, etcétera.

Por otro lado, la educación en medios busca analizar también el contexto de recepción y las prácticas de deconstrucción de los mensajes, a fin de comprender en qué situaciones eligen las audiencias la lectura ofrecida por los medios, y en qué condiciones se dan prácticas de decodificación alternativa o de oposición.

Este enfoque de educación en medios analiza la manera en que, a partir de las representaciones mediáticas, los receptores llegamos a aceptar como naturales ciertos juicios acerca de nosotros mismos y de los otros, cuando nosotros o ellos estamos representados en los medios. Se trata de una educación que propone problematizar las representaciones sociales -la nuestra y la de los otros- en los medios y en la sociedad. En esta perspectiva, la educación en medios analiza la construcción de la identidad en los medios (la mujer, el hombre, la familia, la pobreza, el negro, el indígena, el europeo, el africano) para comprender mejor la relación entre esas representaciones y el mundo real.

Los medios de comunicación participan en la construcción de nuestra identidad. Influyen sobre nuestra noción de género, sobre nuestro sentido de clase, raza o nacionalidad; sobre quiénes somos nosotros y quiénes son ellos. Las imágenes de los medios de comunicación organizan y ordenan nuestra visión del mundo y nuestros valores más profundos: lo que es bueno y lo que es malo, lo que es positivo y lo que es negativo, lo que es moral y lo que es amoral. Los medios nos indican cómo comportarnos ante determinadas situaciones sociales; nos proponen qué pensar, qué sentir, qué creer, qué desear y qué temer. Nos enseñan qué es ser hombre y qué es ser mujer; cómo vestirnos, qué consumir, de qué manera ser popular y evitar el fracaso; cómo reaccionar ante grupos sociales diferentes al nuestro y de qué modo responder a normas, instituciones y valores sociales. 
Las representaciones en los medios producen significados a través de los cuales damos sentido a nuestra experiencia personal y a nuestra función social. Contribuyen a la construcción de la identidad individual y colectiva, ofreciendo respuestas a preguntas tales como quién soy, quién podría ser y qué quiero ser (Hall, 1997).

Los medios, como sistemas de representación, construyen lugares y espacios desde donde los individuos pueden ubicarse y hablar. Nos dicen qué significa ocupar y pertenecer a una posición y a una identidad particulares, y qué se siente al estar excluido de ellas. Proponen sistemas de clasificación y establecen los límites simbólicos entre lo que se incluye y lo que se excluye. Sugieren lo que es normal y definen quién pertenece y quién está fuera de esa normalidad.

Así, una educación en medios propone analizar la manera en la que los medios construyen identidades (nosotros y ellos; yo y el otro) a través de representaciones, en un abordaje que incluye una lectura ideológica del discurso, para luego explorar el modo en el que las audiencias olvidan que esas representaciones son construcciones y las integran natural y normalmente a su vida cotidiana.

Una formación en medios, en suma, es una pregunta constante sobre la manera en la que damos sentido al mundo, y el modo en que otros (los medios) le dan sentido para nosotros. Es interrogar en interés de quiénes operan las representaciones en los medios, qué intenciones persiguen, y qué dicen (y no dicen) de nosotros y de ellos (Ferguson, 1997).

La educación en medios busca comprender la representación del mundo en ellos, para pensar mejor nuestra propia ubicación en ese universo de representaciones, y, sobre todo, en el mundo real. Una educación en medios no se contenta con el análisis de los textos; propone una reflexión crítica sobre los medios y sobre las relaciones sociales representadas en sus mensajes.

Una educación en medios significa desafiar las representaciones tal como aparecen en los medios. ¿Representan los medios a personas como yo? ¿De qué manera? ¿Y a las personas que no son como yo? ¿Qué dicen y qué no dicen de mí y de ellos? ¿Cómo piensan los medios que soy? ¿Por qué? La educación en medios supone que los alumnos descubran y analicen dónde están en ese mundo de representaciones, para poder definir después su relación con el mundo real y participar en su transformación. 


\section{EL LUGAR DE LA ESCUELA}

¿Cuál es el lugar de la escuela en esta perspectiva de educación en medios? El desarrollo de los medios de comunicación y las nuevas tecnologías de la información han llevado a considerar la necesidad de preparar a los jóvenes para que puedan relacionarse críticamente con dicho entorno mediático (Piette, 1996). La escuela no puede tomar a los medios como epifenómenos en el proceso de socialización de los niños. Los estudiantes están siendo formados en la intersección del texto escrito, la imagen electrónica y la cultura popular. Los centros comerciales, la televisión, la música, las historietas, el cine, los videojuegos y otras expresiones de la cultura popular deben convertirse en objetos de conocimiento escolar.

La pedagogía debe redefinir su relación con la cultura y servir como vehículo para su interpretación y mutua potenciación. La educación, entendida como práctica cultural, necesita abrir nuevos espacios en los que los alumnos puedan experimentar y definir qué significa ser productores culturales, ser capaces de leer diferentes textos, y, por supuesto, de producirlos (Giroux, 1996). La escuela debe enseñar a analizar la manera en que esos textos construyen voces e historias, y el modo en que los alumnos se sitúan dentro de esas historias.

Una buena enseñanza es la que se toma en serio la vida de los alumnos. Hablamos de una educación que recupere las experiencias de los estudiantes analizando las formas en que moldean su identidad. De eso trata una educación con sentido: de analizar las experiencias de los estudiantes dentro de un contexto social y político más amplio.

Los alumnos tienen recuerdos, familias, religiones, sentimientos, lenguajes y culturas que les dan voz. Podemos asumir estas experiencias de manera crítica e ir más allá de ellas. Pero no podemos negarlas. Al ser capaces de escuchar las voces de sus alumnos, los docentes se convierten en cruzadores de fronteras (Giroux, 1997) que cuestionan los límites culturales existentes, configuran otros nuevos y permiten que sus alumnos participen en su creación.

La incorporación de la cultura popular a la escuela puede ayudar a los alumnos a entender quiénes son, cómo se definen socialmente, y cómo es y cómo funciona la sociedad en la que viven (Morduchowicz, 2001). 
Tomar en cuenta la cultura popular, que es también la cultura en la que se definen con frecuencia los chicos y los jóvenes a sí mismos, ofrece a los alumnos oportunidades para distanciarse de la literalidad de los mensajes y para comenzar a construir una nueva relación con los medios de comunicación, con la cultura, con la escuela y con el conocimiento.

Invita a los maestros a tomar en cuenta, a valorar y a resignificar los lenguajes, las necesidades, los deseos y las experiencias de los chicos en relación con la cultura cotidiana, con aquella que viven fuera de la escuela.

La pedagogía es, finalmente, la manera a través de la cual aprendemos a vernos a nosotros mismos en relación con el mundo. Ese es el desafío para la escuela actual: integrar la multiplicidad de espacios en los que se produce dicho aprendizaje.

\section{BIBLIOGRAFÍA}

FERGUSON, Robert (1997): «Moyens de communication de masse, éducation et démocratie», en Revue de diffusion des savoirs en éducation, núm. 14, París, Education.

- (1994): "Debates About Media Education and Media Studies in the UK», en Critical Arts Journal, vol. 8, Durban University of Natal.

FERRÉS, Joan (1994): Televisión y educación, Barcelona, Paidós.

GARCíA CANCLINI, Néstor (1999): El consumo cultural: una propuesta teórica, Bogotá, Convenio Andrés Bello.

GIRoux, Henry (1997): Cruzando límites. Trabajadores culturales y políticas educativas, Barcelona, Paidós. lona, Paidós.

- (1996): Placeres inquietantes. Aprendiendo de la cultura popular, Barce-

HALL, Stuart (1997): Representation. Cultural Representations and Signifying Practices, Londres, Sage Publications.

MARTín-BARBERo, Jesús (1999): Recepción de medios y consumo cultural: travesías, Bogotá, Convenio Andrés Bello.

MASTERMAN, Len (1993): La enseñanza de los medios de comunicación, Madrid, Ediciones de la Torre. 
MoRDUCHOWICZ, Roxana (2001): A mí la tele me enseña muchas cosas, Buenos Aires, Paidós. L'Harmattan.

PIETTE, Jacques (1996): Education aux médias et fonction critique, París, 